\title{
ГИС В МОРСКИХ ИССЛЕДОВАНИЯХ: МИРОВОЙ ОПЫТ И ВОЗМОЖНОСТИ ЕГО ПРИМЕНЕНИЯ НА ПРИМЕРЕ ЧЕРНОМОРСКОГО РЕГИОНА
}

\section{Новикова А.М. ${ }^{1}$, Каширина Е.С. ${ }^{2}$, Новиков А.А. ${ }^{2}$, Полонский А.Б. ${ }^{1}$, Панкеева Т.В. ${ }^{3}$}

${ }^{l}$ Федеральное государственное бюджетное научное учреждение «Институт природнотехнических систем», г. Севастополь, Российская Федерачия, e-mail: anelkapi@bk.ru

${ }^{2}$ Филиал Московского государственного университета им. М.В. Ломоносова в г. Севастополе, 2. Севастополь, Российская Федерачия, e-mail: e_katerina.05@mail.ru

${ }^{3}$ Федеральное государственное бюджетное учреждение науки «Институт морских биологических исследований им. А.О. Ковалевского РАН»,

2. Севастополь, Российская Федерачия, e-mail: tatyanapankeеva@yandex.иа

В статье дан краткий обзор работ по использованию геоинформационных систем для морских и прибрежных исследований. Выделены современные тенденции применения аппарата ГИС в изучении климатических, геоботанических, ландшафтных и комплексных геоэкологических исследованиях акваторий океанов и прибрежной зоны морей. Показано эволюционное усложнение стандартной структуры ГИС - переход от простой информационной системы к созданию инфраструктуры пространственных данных с использованием результатов дистанционного зондирования. На примерах двух авторских проектов показаны особенности применения разных типов ГИС для решения задач морских исследований.

Ключевые слова: ГИС, Черное море, Крымский полуостров, кригинг, донные природные комплексы, морские исследования.

\section{Введение}

В последнее время широкое применение получило использование геоинформационных (ГИС) технологий в морских исследованиях, под которыми понимается широкий спектр научных направлений, связанных с изучением морской среды. К таким направлениям относятся:

- экологические исследования - изучение загрязнения морской среды, экосистемные исследования, включая экологический мониторинг;

- океанологические исследования параметров морской среды и их изменчивости на различных пространственно-временных масштабах;

- геофизические исследования шельфовой или прибрежной зон - для обеспечения разработки месторождений полезных ископаемых, исследования динамики геоморфологических процессов и пр.;

- комплексные (междисциплинарные) исследования на основе анализа баз данных по различным компонентам природной среды.

Применение ГИС в океанографии и гидрометеорологии рассмотрено в (Воронцов А.А. и др., 2000; Кондратьев, 2002; Spatial interpolation..., 2007). Авторами сделан вывод о том, что внедрение ГИС в гидрометеорологическую практику произошло стихийно, на основе интуитивного предположения о повышении уровня гидрометеорологического обеспечения за счет использования аппарата ГИС-технологий. 
В то же время любой технический аппарат, каким являются ГИС, обладает ограничениями на область применения. Кроме того, их использование вносит некоторые искажения в исходный набор данных при отображении. Это приводит к необходимости оптимизации сочетания пространственного и временного разрешений получаемой и используемой для решения практических задач гидрометеорологической и океанографической информации, ставит задачу по разработке принципов пространственно-временного обобщения (генерализации) данных. Такая необходимость диктуется все возрастающими рисками при планировании мероприятий по устойчивому развитию акваторий с учетом данных дистанционного зондирования Земли и инструментальных наблюдений на акватории. В работе (Долотов, 2005) сделан вывод о том, что ограничения, связанные с применением стандартных ГИС-инструментов в океанографии, вынуждает использовать, помимо них, и другие средства анализа и отображения данных.

В работе (Калантаевский и др., 2013) представлена разработанная авторами ГИС, использующаяся для экологического мониторинга в нефтегазовом комплексе, в том числе для планирования операций и принятия решений в случае угрозы загрязнения побережья нефтью. ГИС поддерживает интеграцию и обработку различного вида географической и геофизической информации и данных о пространственном положении, составе и чувствительности к загрязнению прибрежных экосистем. Другие авторы (Qin et al, 2017) предлагают программное обеспечение на основе ГИС для прогнозирования дрейфа загрязнителей и их рассеивания (на примере красного прилива), которое обеспечивает улучшенную визуализацию и удобные автоматические инструменты для моделирования в географически привязанной среде. Модель откалибрована с помощью полевых наблюдений и основывается на теории диффузии частиц (дробном броуновском движении). В работе (Гордов и др., 2009) рассматривается применение ГИС для проведения научных исследований, связанных со статистическим анализом архивов пространственно-распределенных геофизических данных, полученных как в результате наблюдений, так и посредством моделирования.

Накоплен значительный опыт применения ГИС-технологий для геоэкологических исследований прибрежных морских экосистем и разработке мер по их защите (Исматова, 2004; Bekkby et al., 2004; Keshavarzi et al., 2015), в том числе прибрежной зоны Мексиканского залива (Harbaugh, 2003), Европы (Moksness et al., 2013), Японии и Тайланда (Goto et al., 2010), а также по разработке сети морских охраняемых акваторий в условиях конфликтного природопользования в Тихоокеанской канадской экономической зоне (Wood, Dragicevic, 2007). Как отмечают авторы работы (Bartlett et al., 1999), специалисты, изучающие прибрежные и морские системы с помощью ГИС, вынуждены решать проблемы, связанные с отображением высокодинамичных и многомерных сред, не имеющих четких границ.

Комплексная экологическая оценка и зонирование океана осуществлена исследователями из Тайваня (Chien et al., 2012) с целью обеспечения устойчивого развития, охраны и сохранения природных ресурсов. Основываясь на текущем использовании морских ресурсов в приливных зонах, прибрежных районах, внутренних водах и территориальных водах, авторами предложено выделять одиннадцать типов функциональных областей.

Кроме экологических исследований прибрежной зоны, встречаются работы по классификации морского дна согласно воздействию абиотических факторов (с разной степенью значимости), таких как волновое воздействие, соленость, глубина, средняя и максимальная орбитальные скорости на дне, разности температур между теплым и холодным сезонами, солнечная радиация и тип осадков (Urbański et al., 2008). Предлагаемый авторами метод разработки типологии в среде ArcGIS состоит из 
последовательности операций: кластеризации, анализа дендрограммы и классификации с использованием метода максимального правдоподобия. Это позволяет создавать тематические карты дна высокого разрешения (на примере Гданьского залива в южной части Балтийского моря), а также использовать их в экологических моделях.

Не менее интересны междисциплинарные эколого-геофизические исследования, решающие задачи пространственного планирования в морских акваториях с помощью ГИС. Результаты работы авторов, опубликованные в (Gimpel et al., 2015), иллюстрируют, как синергизм может быть реализован между такими конкурирующими видами природопользования, как морская ветроэнергетика и интегрированная мультитрофическая аквакультура в исключительной экономической зоне Германии в Северном море. ГИС в сочетании с мультикритериальной оценкой помогла определить участки оптимального расположения проектируемых объектов на основе данных о состоянии окружающей среды. Группа исследователей из Греции (Vasileiou et al., 2017) разработала методологическую основу для определения наиболее подходящих частей акваторий для размещения гибридных ветро-волновых энергетических систем. С помощью ГИС созданы карты, представляющие результат использования критерий исключения тех или иных акваторий. Они связанны с ограничениями использования, а также с экономическими, техническими и социальными требованиями, которые на втором этапе оценивания подвергаются аналитической иерархической оценке для акваторий, прошедших первый этап исключения.

В последнее десятилетие все чаще используется метод интеграции ГИС с данными дистанционного зондирования Земли (Д33). Группа исследователей (Pasqualini et al., 2005) рассмотрела возможность использования космических снимков со спутника SPOT 5 с разрешением пикселя 10 и 2,5 м для картографирования сообществ водорослей в Средиземном море. Спутниковые данные, в частности вегетационный индекс NDVI, помимо непосредственного описания состояния ландшафтов, могут выступать и в качестве индикаторов климатических изменений, особенно в районах экосистем с низкой устойчивостью. Оценка изменения фитомассы, которая тесно коррелирует с климатическими параметрами: ростом средних летних температур, удлинением периода вегетации и количеством накопленного за этот период тепла, широко применяется для индикации изменения климата по состоянию растительных сообществ в разных регионах мира (Bhatt et al.,2010; Walker et al., 2003; 2010).

В мировой практике с 1994 г. внедряется следующий уровень ГИС инфраструктура пространственных данных (ИПД), или информационнотелекоммуникационная система. Основное отличие ИПД от ГИС - существование первой в сети Интернет, где к ней имеется всеобщий доступ (как правило, платный). ИПД - это, фактически, распределенная ГИС. Примером ИПД прибрежных экосистем может служить британская программа «COASTMAР», преобразованная затем в расширенную программу «OceansMaр» и реализуемую в рамках web-приложения (http://oceansmap.com/). Вебинтерфейс позволяет визуализировать и анализировать различные метео- и океанографические данные. Она также может быть использована для проработки сценариев нефтяных или химических разливов, запуска моделей погодных условий на основе свежих метеоданных, размещенных на OceansMapServer. Среди новейших разработок в области веб-ГИС технологий стоит упомянуть работу по мониторингу и прогнозированию сейш в мелководной части Северного Цзянсу, Китай (Qin, Lin, 2017). Датчики in situ выполняют автоматический и непрерывный мониторинг состояния морской среды, а численные модели дают оценку метеорологических и физических океанографических параметров. Веб-инфраструктура ГИС облегчает доступ к данным и 
автоматически создает карты в режиме реального времени, что в итоге представляет собой систему раннего предупреждения чрезвычайных сейшевых заплесков в прибрежной зоне.

Для Черноморского региона также разработано несколько ГИС. Самая первая и наиболее полная на настоящее время - это ГИС «Чёрное море» (ГИС «Черное море», 1999). В 2009 г. в странах бассейна Чёрного моря стартовал проект «EnviroGrids» («Формирование потенциала по наблюдению за Черноморским бассейном в рамках поддержки устойчивого развития территории»), в результате реализации которого планировалось создание междисциплинарной ГИС (Лычак, Бобра, 2010). Также различными исследователями разрабатывается ряд проблемных ГИС: для изучения биологической продуктивности Чёрного моря (Лисицин, 2002), мониторинга нефтяных загрязнений (Затягалова, Иванов, 2007; Калантаевский и др., 2013; Воронцов А.А. и др., 2000), а также для различных океанографических приложений (Устойчивость и эволюция..., 2012; Новикова, 2016).

Далее на конкретных примерах будет рассмотрено использование технологий ГИС в нескольких областях - для получения полей физических параметров морской среды в региональных климатических исследованиях, а также для оценки состояния донных прибрежных комплексов по данным гидроботанических исследований.

\section{Результаты и обсуждение}

Возможности открытой ГИС QGIS для изучения гидрофизических полей. В океанологии традиционными инструментами обработки гидрофизических данных служат, как правило, специализированные статистические программные продукты, такие как MatLab, Surfer, R и прочие, тогда как на ГИС пока что обращено мало внимания. Это связано не столько со спецификой организации баз данных, сколько с тем, что пока не существует такого ГИС-продукта, который был бы способен проводить многомерный пространственно-временной анализ.

В целях разработки методики применения современных ГИС-технологий в океанологии были проанализированы функциональные особенности программного обеспечения (ПО) ГИС проприетарных и с открытым исходным кодом. Перспективным ПО, таким образом, можно назвать открытую ГИС QGIS (Quantum Geographic Information System) (QGIS User..., 2016), интегрирующую в свой набор инструментов программные модули открытых ГИС (таких, как SAGA и GRASS) и обладающую набором модулей, позволяющих создавать, обрабатывать и анализировать массивы океанологических данных. В ней также возможно создание пользователем специализированных приложений на языке программирования Python. Некоторый опыт использования программы для климатических исследований представлен в работах (Krasowski, 2011; Новикова и др., 2016; Pabón-Caicedo, Alarcón-Hincapié, 2016).

Для анализа гидрофизических полей с помощью ГИС-технологий в настоящей работе были выбраны два массива по температуре поверхностных вод Чёрного моря - с большой и малой плотностью станций из базы данных (БД) Института природно-технических систем (GIS Института..., 2016): за август 1955-1999 гг. и за июль-август 1989 г. (рис. 1). Для оценки погрешности процедур интерполяции использовался метод кросс-валидации, позволяющий получить значения невязки, среднеквадратического отклонения (СКО) и смещения интерполяционного поля, подробно описанный в работе (Новикова и др., 2016).

При анализе полей основных параметров морской среды перед исследователем обычно встает вопрос о выборе процедуры получения значения этих параметров в узлах регулярной сетки. Для решения данной задачи используются алгоритмы интерполяции или геостатистический анализ, который в QGIS представлен широким рядом модулей в панели 
«Инструменты анализа», в том числе использующих ресурсы сторонних ГИС (SAGA и GRASS). Наиболее часто в океанологии используется метод кригинга, который относится к геостатистическим математическим моделям, представляющим оптимальную интерполяцию.

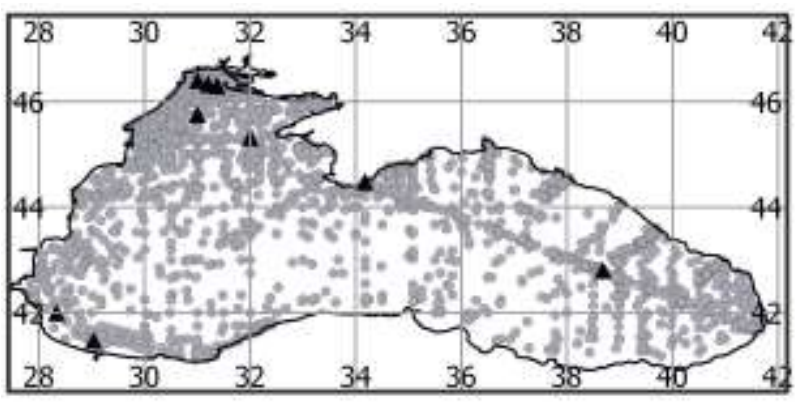

a)

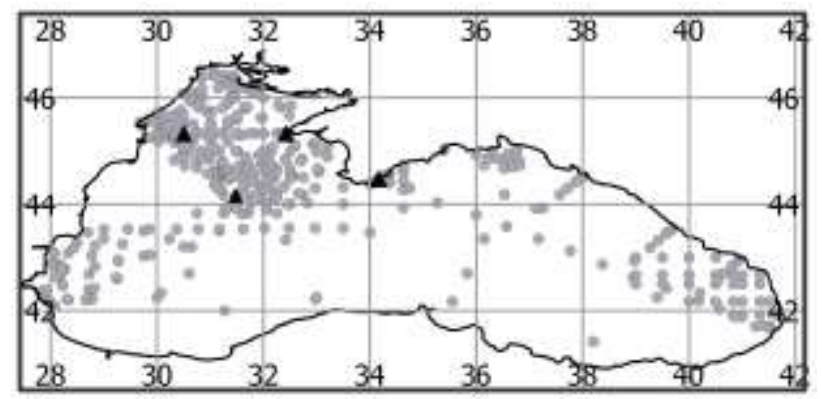

б)

Рис. 1. Распределение точек с данными по акватории Чёрного моря а) за август 1955-1999 гг., б) за июль-август 1989 г. Треугольниками обозначены станции, использованные для кросс-валидации.

Термин «Кригинг» служит для обозначения семейства алгоритмов линейной пространственной регрессии (Демьянов и др., 2010). Все интерполяторы семейства кригинга являются различного рода модификациями базового линейного регрессионного оценивателя $Z *(\boldsymbol{x})$, определяемого следующим образом:

$$
Z^{*}(\boldsymbol{x})-m(\boldsymbol{x})=\sum_{i=1}^{n(x)} \lambda_{i}(\boldsymbol{x})\left[Z\left(\boldsymbol{x}_{i}\right)-m\left(\boldsymbol{x}_{i}\right)\right]
$$

где $\lambda_{i}(\boldsymbol{x})$ - весовые коэффициенты, относящиеся к данным $Z\left(\boldsymbol{x}_{i}\right) ; m(\boldsymbol{x}), m\left(\boldsymbol{x}_{i}\right)$ математические ожидания случайных переменных $Z(\boldsymbol{x})$ и $Z\left(\boldsymbol{x}_{i}\right) ; n$ - количество оцениваемых точек.

Число данных, использующихся при оценке, и значения весовых коэффициентов могут меняться в зависимости от местоположения оцениваемой точки $\boldsymbol{x}$ (Демьянов и др., 2010). При условии, что процесс имеет стационарное математическое ожидание, процедура оценивания называется обычным кригингом. Если же процесс не является стационарным (в данных присутствует значимый тренд), используют процедуру универсального кригинга (Кошель и др., 2001). В данной работе проанализированы оба метода - обычный и универсальный.

Возможность дополнительной настройки модуля «Кригинг» с помощью множества параметров делает данный метод наиболее мощным инструментом интерполяции. Анализ полей, полученных обычным и универсальным методами кригинга в QGIS, показал, что на результаты интерполяции оказывают влияние все задаваемые в модулях параметры, начиная от размерности интерполяционной сетки и заканчивая радиусом вариограммы и минимальным количеством взятых для анализа точек. Параметры вариограммы задавались с учетом максимального коэффициента достоверности аппроксимации функции (Кд) модельной вариограммы.

Оба вида кригинга позволяют получать поля среднеклиматических значений температуры, приближенные к их естественному распределению в морской среде, как для массива с достаточно большой плотностью данных (рис.1a, 3), так и для массива с малой плотностью (рис.1б, 2). Экспериментальные вариограммы показали наличие тренда для массива, представленного на рис. 1а, и так называемого «эффекта включений» в данных (когда кривая вариограммы пересекает заданный порог, а затем периодически изменяется в некоторый окрестности этого порога). 


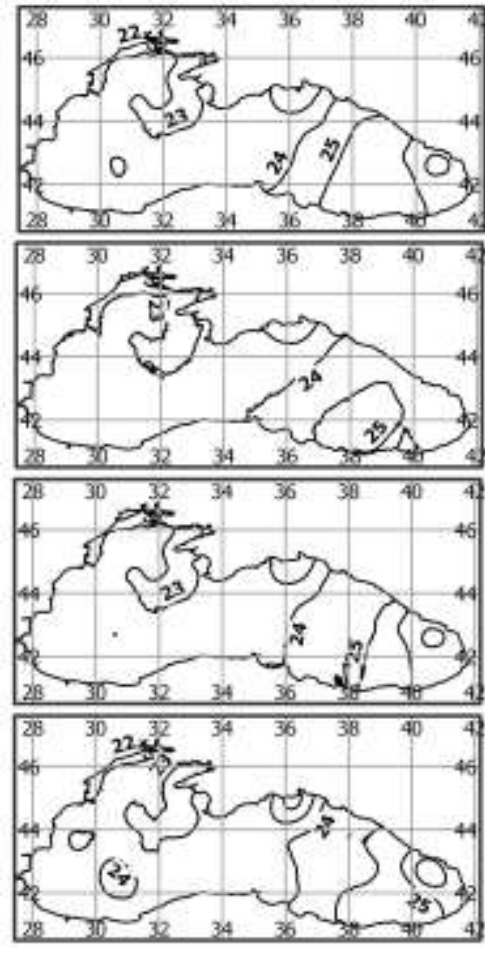

a)

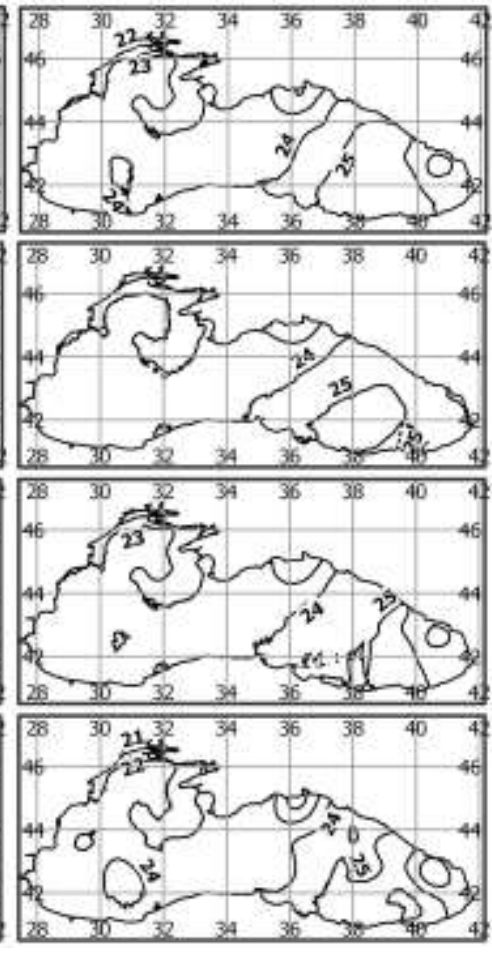

б)
1)

2)

3)

4)

Рис. 2. Поля температуры поверхностных вод за июль-август 1989 г., полученные методом а) обычного и б) универсального кригинга с использованием 1) линейной, 2) квадратической, 3) кубической и 4) экспоненциальной функций модельной вариограммы.

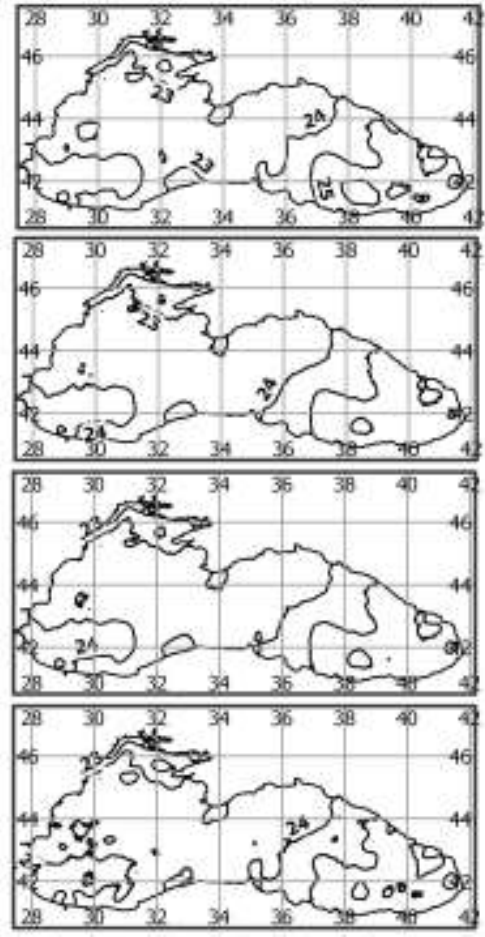

a)

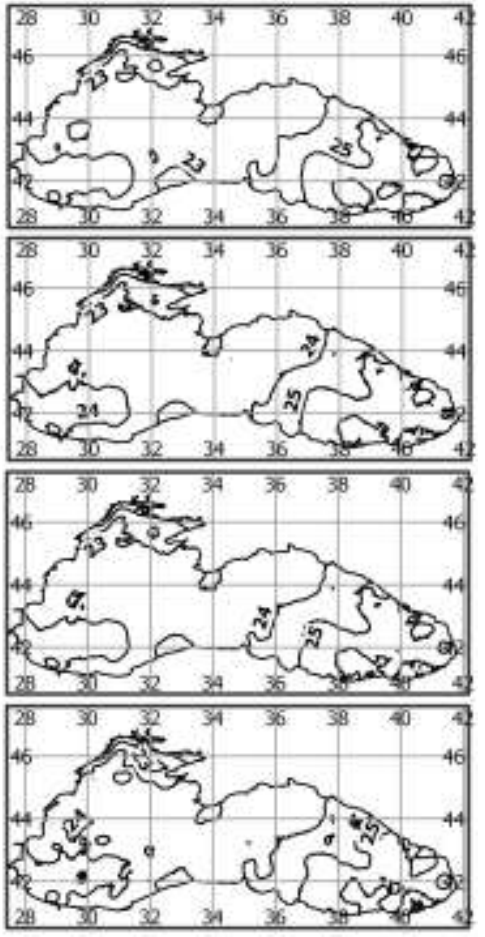

б)
1)

2)

3)

4)

Рис. 3. Поля средней температуры поверхностных вод за август 1955-1999 гг., полученные методом а) обычного и б) универсального кригинга с использованием 1) линейной, 2) квадратической, 3) кубической и 4) экспоненциальной функций модельной вариограммы. 
Подбор радиуса влияния вариограммы исходя из максимального Кд и вида графиков функций модельной вариограммы уточняет весовые коэффициенты каждой станции в уравнении (1). Настройка оптимального размера узла интерполяционной сетки, а также параметров поиска для каждого набора данных и масштаба анализируемого явления ускоряет процедуру интерполяции.

Универсальный кригинг дал меньшие, чем обычный значения смещения (в среднем - около минус $0.25^{\circ} \mathrm{C}$ ) и среднеквадратического отклонения (в среднем - около $0.65^{\circ} \mathrm{C}$ ) при кросс-валидационной оценке, что говорит о положительном влиянии на процедуру кригинга учета пространственного тренда, хорошо заметного на экспериментальной вариограмме массива с достаточно большой плотностью данных.

Кросс-валидация дала практически идентичные значения смещения (в среднем около минус $0.52^{\circ} \mathrm{C}$ ) и среднеквадратической погрешности (в среднем - около $0.25^{\circ} \mathrm{C}$ ) соответствующих функций модельной вариограммы при использовании и обычного, и универсального кригингов для поля с малой плотностью данных. Вместе с тем, в полях, полученных методом универсального кригинга, виден резкий скачок функции, что обусловлено большой неравномерностью данных измерений. Экспериментальная вариограмма массива данных указывает на необходимость тщательного подбора функции модельной вариограммы.

Наилучшие результаты при интерполяции полей для набора данных с малой обеспеченностью измерениями показал обычный кригинг (рис. 2a), а для набора с большим количеством данных - универсальный (рис. 3б). Частично это связано с тем, что во втором случае пространственно-временная выборка экспериментальных данных относится к разным годам и десятилетиям. При условии, что статистическая структура поля температуры верхнего слоя вод Черного моря изменяется от одного десятилетия к другому (Полонский, Шокурова, 2008), а метод универсального кригинга позволяет (по крайней мере, частично) учесть эти изменения, такой результат становится понятным. Вообще, из-за того, что очень часто анализируемые массивы океанологических данных характеризуются неравномерной пространственно-временной структурой, остро стоит вопрос о достоверности получаемых результатов интерполяции. QGIS позволяет провести как качественную (визуальную), так и количественную (методом кросс-валидации) оценку качества получаемых полей, используемых затем для описания пространственновременной изменчивости параметров морской среды с известной погрешностью. Причем можно добиться минимизации этой погрешности за счет использования интерполяционной процедуры, фактически близкой к обобщенному методу оптимальной интерполяции. Одновременно, можно использовать все средства ГИС-технологий. Таким образом, перед исследователями открываются новые возможности использования открытой ГИС в морских климатических исследованиях, как для сбора данных, так и для выборки, статистической обработки и анализа.

\section{Ландшафтное картирование донных природных комплексов (ДПК) с использованием ГИС-технологий.}

Исследование ДПК с применением современных методов, таких как использование подводной видеотехники и многолучевое сканирование с целью составления геоинформационных ландшафтных карт, является одним из актуальных направлений современной географии. Однако, для Черного моря сведения о подводных ландшафтах малочисленны, особенно в прибрежной зоне Крымского полуострова, которая характеризуется высоким их разнообразием и уникальностью.

В качестве модельного полигона для исследования и картографирования подводных ландшафтов выбрана прибрежная зона Южного берега Крыма (ЮБК) в административных границах г. Севастополя - урочище Батилиман - бухта Ласпи 
(Панкеева, 2014). Карты составлены на основе опубликованных и архивных материалов экспедиций, проведённых летом 2008 г. отделом биотехнологий и фиторесурсов Института морских биологических исследований (ИМБИ). Сведения о донных компонентах ландшафтов, полученные в ходе водолазного описания, видео и фотосъемки, оформляли графически в виде ландшафтных профилей. Основу ландшафтного профиля составляет батиметрическая кривая, на которой отражены литофациальные разности донных осадков и массовые виды макрофитов. На ландшафтном профиле выделены границы ДПК, которые представляют однотипные участки морского дна, приуроченные к одной мезоформе рельефа, имеющие одинаковые по происхождению и составу слагающие горные породы и характерные фитоценозы. При описании природных особенностей подводного рельефа заполнялись интерпретационные таблицы, прилагаемые к профилю. Для создания ландшафтной карты использован программный пакет MapInfo Professional версии 11.0 и электронная версия навигационной карты б. Ласпи. Географическую привязку границ ДПК и определение их площади осуществляли с помощью программы MapInfo c корректировкой по данным дистанционного зондирования (Google-снимки). Сопряженный анализ карт литологического состава и сведений батиграфических водолазных съемок позволил провести экстраполяцию участков дна со сходными параметрами для выделения границ ДПК, которые отражены на обобщенной ландшафтной карте б. Ласпи (рис. 4). Применение ГИС-технологиий позволило не только отразить пространственную структуру ДПК, но и проанализировать ее изменения.

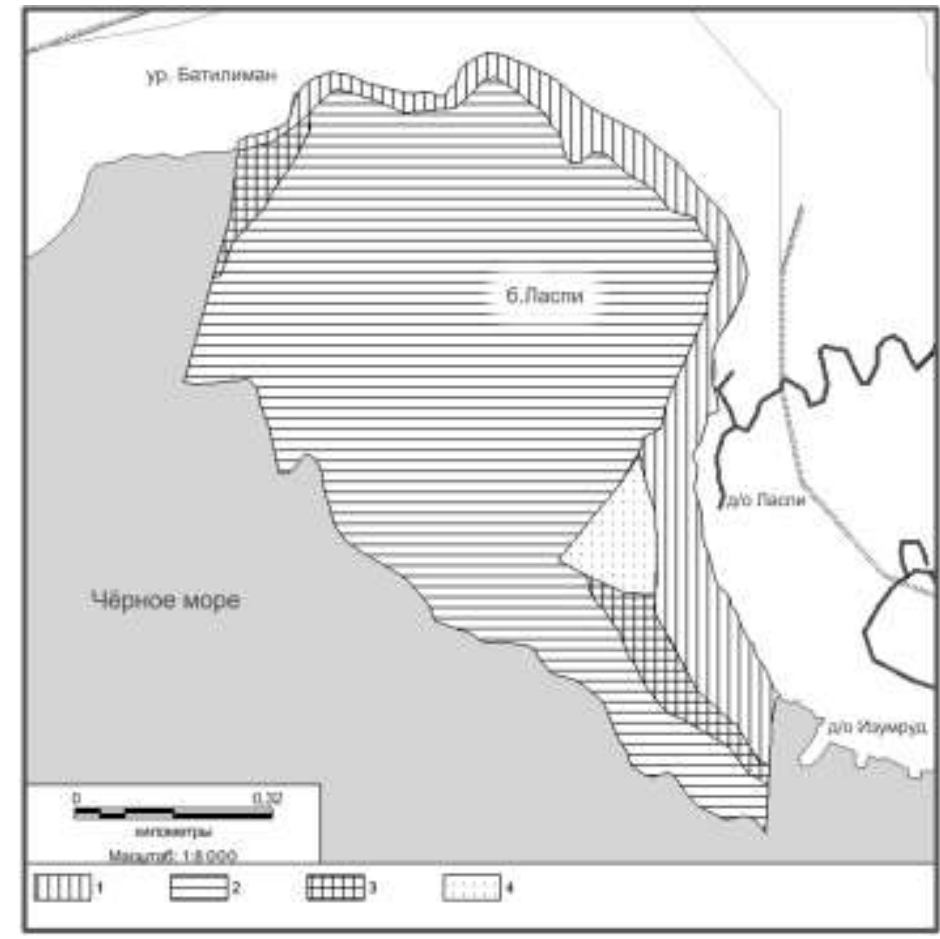

Рис. 4. Схема ландшафтной структуры акватории б. Ласпи. Условные обозначения: 1 подводный береговой абразионный склон, сложенный псефитовыми отложениями с преобладанием видов цистозиры и высокой долей эпифитного комплекса; 2 слабонаклоненная аккумулятивная равнина, сложенная алеврито-псаммитовыми отложениями с сильно деградированным разреженным сообществом макрофитов и преобладанием видов кладофоры; 3 - слабонаклоненная аккумулятивная равнина, сложенная псефито-псаммитовыми отложениями с преобладанием цистозиры бородатой и филлофоры ребристой; 4 - абразионно-аккумулулятивная терраса, сложенная псефито-псаммитовыми отложениями с преобладанием кодиума червеобразного и стилофоры нежной. 
Несмотря на то, что в настоящее время ландшафтный подход получил широкое применение в морских исследованиях, в гидроботанике его используют редко. Однако ведущим компонентом ДПК выступает макрофитобентос, где в настоящее время произошли существенные структурные изменения: отмечается снижение запасов фитомассы, изменения видовой структуры сообществ, уменьшение зоны распространения сообществ водорослей - фитали и т.д. Донная растительность реагирует на изменения морской среды, что позволяет использовать ее при изучении динамики ДПК.

Ландшафтные карты выступают картографической основой для проведения оценки экологического состояния береговой зоны, а ландшафтные контуры - территориальнооперационными единицами. $\mathrm{C}$ помощью ГИС-технологий рассчитана биомасса макрофитов (растительной компоненты ландшафта) для каждого типа местности, проведен анализ временной динамики фитомассы.

Для изучения растительной компоненты ДПК б. Ласпи с помощью ГИСтехнологий создана серия карт и атрибутивных таблиц, содержащих данные о биомассе, запасах фитомассы и т.д., которые позволили выявить особенности пространственного распределения и охарактеризовать динамику популяций ключевых видов макрофитов: цистозиры (Cystoseira barbata C. Ag. и C. crinita (Desf.) Bory), филлофоры (Phyllophora crispa (Huds.) P.S. Dixon = Ph. nervosa (DC) Grev.) и зостеры (Zostera marina L). Сравнительный анализ общих запасов макрофитов и запасов цистозиры исследованных акваторий показал, что их максимальная величина зарегистрирована на участке м. Айя база Батилимана, а минимальная - в районе д/о Ласпи - д/о Изумруд (Миронова, Панкеева, 2016). Полученные результаты, возможно, объясняются относительно благополучным состоянием морской среды, т.к. часть этой акватории (Мыс Айя) относится к ландшафтному заказнику общегосударственного значения и имеет охранный статус заповедания, предполагающий ограниченный доступ в этот район. Разреженные скопления макрофитов на участке вершина бухты Ласпи - д/о Изумруд связаны с высоким уровнем эвтрофирования и низкой прозрачностью воды в этой части акватории, где отмечены значительная антропогенная нагрузка и активная застройка вблизи уреза, несмотря на то, что район между б. Ласпи и м. Сарыч является прибрежно-аквальным комплексом (ПАК), относящимся к памятнику природы местного значения.

Исследованные участки прибрежной акватории б. Ласпи характеризуются различной трансформацией структуры донных сообществ за период с 80-х прошлого века по настоящее время. Так, очевидно, восстановительная сукцессия цистозировых фитоценозов, наблюдаемая в верхней и средней сублиторальной зонах на участках (база Батилимана - вершина бухты - д/о Ласпи - д/о Изумруд) с 1983 по 1998 гг., обусловленная некоторым улучшением качества среды, сменилась их деградацией за период с 1998 по 2014 гг. из-за чрезмерной рекреационной нагрузки, связанной с массовым строительством в непосредственной близости от побережья. Наиболее негативные изменения донной растительности, вызванные увеличением уровня загрязнения воды, выявлены в акватории участков вершина бухты - д/о Ласпи - д/о Изумруд.

Применение ГИС-технологий к изучению ДПК дает возможность отразить региональные закономерности их пространственного распространения, определить приоритетные территории и акватории для заповедания, провести функциональное зонирование и способствовать формированию экологической сети морских охраняемых территорий, выработать принципы рационального природопользования в прибрежной зоне. 


\section{Выводы}

Эффективность применение ГИС в морских исследованиях объясняется возможностью решения проблемы адекватного отображения характеристик изменчивости морской среды различных пространственно-временных масштабов. При этом появляется возможность провести не только качественный картографический анализ расположения донных прибрежных комплексов, но и оценить их биомассу с использованием современных данных дистанционного зондирования и натурных съёмок. ГИС-технологии позволяют проводить сопряжённей анализ состояния донных природных комплексов и океанологических параметров на основе ландшафтного картирования.

Результаты исследования показывают широкие возможности использования открытой ГИС в океанологии благодаря наличию целого ряда специализированных плагинов и встроенных функций. При корректно подобранных параметрах в интерполяционных модулях можно получать поля океанологических параметров с минимальной ошибкой для последующего их использования как в научных целях, так и для планирования устойчивого развития Черноморского региона.

\section{Список литературы}

1. Воронцов А.А., Жуков Ю.Н., Федорова Е.В. Применение геоинформационных систем для отображения информации о морской природной среде. [Электронный ресурс]. Режим доступа: http://loi.sscc.ru/gis/public/ocean_gis.htm (дата обращения: 21.04.2017).

2. ГИС «Черное море» / под ред. А.М. Берлянта, В.О. Мамаева, О.Р. Мусина. - М.: 1999. $-60 \mathrm{c}$.

3. Гордов Е.П., Окладников И.Г., Титов А.Г. Разработка Веб-ГИС системы для статистического анализа больших архивов пространственно распределенных данных при проведении комплексных геофизических исследований // Российский научный электронный журнал. - 2009. - Том 12. - Вып. 1. [Электронный ресурс]. - Режим доступа :http://www.elbib.ru/index.phtml?page=elbib/rus/journal/2009/part1/GOT (дата обращения: 21.04.2017).

4. GIS Института природно-технических систем / В.В. Мельников, А.Б. Полонский, А.А. Котолупова [и др.] // Системы контроля окружающей среды. - 2016. - Вып. 4 (24). C. $49-55$.

5. Долотов B.В. ГИС и натурные наблюдения - проблемы и решения // Экологическая безопасность прибрежной и шельфовой зон и комплексное использование ресурсов шельфа. - 2006. - № 13. - С. 227-232.

6. Затягалова В.В., Иванов А.Ю. Мониторинг нефтяных загрязнений в море с помощью ГИС-технологии // Материалы 8-ой Всероссийской научно-практической конференции «Геоинформатика в нефтегазовой и горной отраслях», 2007. [Электронный ресурс]. Режим доступа:http://gisa.ru/35856.html (дата обращения: 21.04.2017).

7. Исматова X.P. Формирование геоинформационной модели развития экологически опасных ситуаций прибрежной территории Каспийского моря // Современные проблемы дистанционного зондирования Земли из космоса. - 2004. - С. 459-466.

8. Калантаевский Ю.С., Александрова А.В., Ксандопуло С.Ю., Левчук А.А., Соловьева Ж.П. Применение географических информационных систем для экологического мониторинга в нефтегазовом комплексе // Политематический сетевой электронный научный журнал Кубанского государственного аграрного университета. - 2013. - №86(86) - С. 826-835. 
9. Кондратьев К.Я. Изменение глобального климата: реальность, предположения и вымысел // Исследование Земли из космоса. - 2002. - № 1. - С. 3-31.

10. Лисииьын Б.E. Картографическое исследование биологической продуктивности морских акваторий: на примере Черного моря / Диссертация на соискание степени кандидата географических наук. - М.: 2002.- 172 с.

11. Лычак А.И., Бобра T.В. Проект EnviroGRIDS в Черноморском бассейне и современные тенденции развития ГИС-технологий // Ученые записки ТНУ, Сер. География. - 2010. - Том 23 (62). - №2. - С. 174-182.

12. Миронова Н.В., Панкеева Т.В. Многолетние изменения запасов макрофитов и их связь с ландшафтной структурой дна (Бухта Ласпи, Крым, Чёрное море) // Современные концепции экологии биосистем и их роль в решении проблем сохранения природы и природопользования: материалы Всерос. (с междунар. участием) науч. школы-конф., посвящ. 115-летию со дня рождения А.А. Уранова (Пенза, 10-14 мая 2016 г.) / под ред. Н.А. Леоновой. - Пенза, 2016 - С. 389-392

13. Новикова A.M. Открытая ГИС в океанологии: опыт использования QGIS в целях планирования устойчивого развития Черноморского региона // Проблемы безопасности в современном мире: тезисы докладов I Черноморской научнопрактической конференции МГУ / Под ред. И. С. Кусова. - Севастополь, 2016. - С. $75-$ 76.

14.Новикова А.М., Полонский А.Б., Новиков А.А. Сравнение возможностей интерполяционных модулей QGIS для морских климатических исследований при работе с массивом данных малой обеспеченности // ИнтерКарто/ИнтерГИС 22. Геоинформационное обеспечение устойчивого развития территорий в условиях глобальных изменений климата: материалы Междунар. науч. конф. Т. 1. - М., 2016. C. $76-88$.

15. Панкеева Т.В., Мильчакова Н.А., Миронова Н.В., Александров В.В., Каширина Е.С., Ковардаков С.А., Рябогина В.Г. Ландшафтный подход к оценке состояния макрофитобентоса в условиях конфликтного природопользования // Экологическая безопасность прибрежной и шельфовой зоны и комплексное использование ресурсов шельфа. - 2014. - Т. 29. - С. 70-80.

16. Полонский А.Б., Шокурова И.Г. Статистическая структура крупномасштабных полей температуры и солености в Черном море // Морской гидрофизический журнал. - 2008. - №1. - С.51-65.

17. Устойчивость и эволюция океанологических характеристик экосистемы Черного моря / Под ред. В.Н. Еремеева, С.К. Коновалова. - Севастополь, 2012. - 357 с.

18. Bartlett D.J., Wright, D.J. Epilogue // Marine and Coastal Geographical Information Systems, London: Taylor \& Francis. 1999. P. 295-315.

19. Bekkby T., Rinde E., Rosenberg R., Bakkestuen V., Erikstad L. The effect of terrain structures and environmental factors on the distribution marine habitats // ICES CM 2004. P. 13.

20. Bhatt U. S., Walker D. A., Raynolds M. K. et al. Circumpolar Arctic Tundra Vegetation Change Is Linked to Sea Ice Decline // Earth Interactions. 2010. Vol. 14, N 8. P. 1-20.

21. Chien L.-K., Tseng W.-C., Chang C.-H., Hsu C.-H. A study of ocean zoning and sustainable management by GIS in Taiwan // Ocean \& Coastal Management. 2012. Vol. 69. P. 35-49.

22. Gimpel A., Stelzenmüller V., Grote B., Buck B.H., Floeter J., Núñez-Riboni I., Pogoda B., Temming A. A GIS modelling framework to evaluate marine spatial planning scenarios: Colocation of offshore wind farms and aquaculture in the German EEZ // Marine Policy. 2015. Vol. 55. P. 102-115. 
23. Goto S., Fan H.-S., Sakai T. Risk communication for oil spill accident using geo-informatics and SNS // International Archives of the Photogrammetry, Remote Sensing and Spatial Information Science, Volume XXXVIII, Part 8. Kyoto, Japan. 2010. P. 213-218.

24. Harbaugh $S$. Current and future geographic information system projects within the eastern Gulf of Mexico, and the potential for one universal application // Int. Oil Spill Conference 2003. British Columbia, Canada

25. OcaensMap [Электронный ресурс]. - Режим доступа: http://oceansmap.com/ (дата обращения: 21.04.2017).

26. Keshavarzi B., Ebrahimi P., Moore F. A GIS-based approach for detecting pollution sources and bioavailability of metals in coastal and marine sediments of Chabahar Bay, SE Iran // Chemie der Erde - Geochemistry. 2015. Vol. 75. Is. 2. P. 185-195.

27. Krasowski W. Możliwości wykorzystania Quantum GIS w wizualizacji, przetwarzaniu I analizie prognostycznych danych meteorologicznych. Politechnika Wrocławska, 2011. $70 \mathrm{p}$.

28. Moksness E., Dahl E., Støttrup J. Global Challenges in Integrated Coastal Zone Management, Vol II. John Wiley \& Sons, Oxford, UK. 2013. 251 p.

29. Pabón-Caicedo J.D., Alarcón-Hincapié J.C. El effecto del cambio climatico sobre las zonas aridas y semiaridas de Colombia // ИнтерКарто/ИнтерГИС 22. Геоинформационное обеспечение устойчивого развития территорий в условиях глобальных изменений климата: материалы Междунар.науч. конф. Т. 1. - М., 2016. - С. 56-62.

30. Pasqualini V., Pergent-Martini C., Pergent G. Use of SPOT 5 for mapping seagrasses: An application to Posidonia oceanica // Remote Sensing of Environment. 2005. 94. P. 39 - 45.

31. QGIS User Guide: QGIS Project. http://docs.qgis.org/2.0/ru/docs/user_manual/, 2016 (датаобращения: 20.10.2016).

32. Qin R., Lin L. Development of a GIS-based integrated framework for coastal seiches monitoring and forecasting: A North Jiangsu shoal case study // Computers \& Geosciences. 2017. Vol. 103. P. 70-79.

33. Qin R., Lin L. Kuang C., Su T.-C., Mao X., Zhou Y. A GIS-based software for forecasting pollutant drift on coastal water surfaces using fractional Brownian motion: A case study on red tide drift // Environmental Modelling \& Software. 2017. Vol. 92. P. 252-260.

34. Spatial interpolation for climate data: the use of GIS in climatology and meteorology / edited by Dobesch H., Dumolard P., Dyras I. Great Britain: ISTE Ltd, 2007. 284 p.

35. Urbański J.A., Grusza G., Chlebus N, Kryla L. A GIS-based WFD oriented typology of shallow micro-tidal soft bottom using wave exposure and turbidity mapping // Estuarine, Coastal and Shelf Science. 2008. Vol. 78. Is. 1. P. 27-37.

36. Vasileiou M., Loukogeorgaki E., Vagiona D.G. GIS-based multi-criteria decision analysis for site selection of hybrid offshore wind and wave energy systems in Greece // Renewable and Sustainable Energy Reviews. 2017. Vol. 73. P. 745-757.

37. Walker D. A., Bhatt U. S., Comiso J. C. et al. The Arctic Report Card: Update for 2010. [Электронный pecypc]. - Режим доступа: ftp://ftp.oar.noaa.gov/arctic/documents/ArcticReportCard_full_report2010.pdf (дата обращения: 21.04.2017).

38. Walker D. A., Epstein H. E., Jia G. J. et al. Phytomass, LAI, and NDVI in northern Alaska: Relationships to summer warmth, soil $\mathrm{pH}$, plant functional types, and extrapolation to the circumpolar Arctic // Journal of Geophysical Research. 2003. Vol. 108. Is. D2. P. 1-7.

39. Wood L.J., Dragicevic S. GIS-based multicriteria evaluation and fuzzy sets to identify priority sites for marine protection // Biodivers. Conserv. 2007. Vol. 16. P. 2539-2558 


\section{GIS IN MARINE RESEARCH: WORLD EXPERIENCE AND THE POSSIBILITY OF ITS APPLICATION ON THE EXAMPLE OF THE BLACK SEA REGION}

Novikova A.M. ${ }^{1}$, Kashirina E.S. ${ }^{2}$, Novikov A.A. ${ }^{2}$, Polonsky A.B. ${ }^{1}$, Pankeeva T.V. ${ }^{3}$

${ }^{1}$ Institute of Natural and Technical Systems, Sevastopol, Russian Federation, e-mail: anelkapi@bk.ru

${ }^{2}$ Branch of M.V. Lomonosov Moscow State University in the city of Sevastopol, Russian Federation, e-mail:e_katerina.05@mail.ru

${ }^{3}$ The A.O.Kovalevsky Institute of Marine Biological Research of RAS, Sevastopol, Russian Federation, e-mail: tatyanapankeeva@yandex.ua

The article gives a brief overview of the geographical information systems used for the purposes of marine research. Modern trends in the application of the GIS in the study of climatic, geobotanic, landscape and complex geoecological researchs of the oceans and coastal zones of the seas are outlined. There is shown an evolutionary complication of the standard GIS structure - the transition from a simple information system to creation of the infrastructure for spatial information using remote sensing data. Examples of authors' two projects show the features of applying different types of GIS for marine research.

Key words: GIS, Black Sea, Crimean peninsula, kriging; bottom natural complexes, marine research.

Поступила в редакциию 12.05.2017 2. 